\title{
The analytical application for cement using X-Ray diffraction and X-Ray fluorescence spectrometer
}

\author{
Ji Eun Jung ${ }^{1}$, Yu Rim Jang ${ }^{2}$, Ki-Wook Kim ${ }^{1}$, Sangcheol Heo ${ }^{1}$ and Ji-Sook Min ${ }^{1, \star}$ \\ ${ }^{I}$ National Forensic Service, 139 Jiyang-Ro, Yangchon-Gu 158-707, Korea \\ ${ }^{2}$ Ewha Womens University, 211-1 Daehyun-Dong, Seodaemun-Gu 120-750, Korea
}

(Received August 5, 2013; Revised August 29, 2013; Accepted August 29, 2013)

\section{X-Ray Diffraction과 X-Ray Fluorescence를 이용한 시멘트 비교 분석 \\ 정지은 ${ }^{1}$ - 장유림 ${ }^{2}$ - 김기욱 ${ }^{1} \cdot$ 허상철 ${ }^{1} \cdot$ 민지숙 ${ }^{1}{ }^{\star}$ \\ ${ }^{1}$ 국립과학수사연구원 법과학부 화학분석과, ${ }^{2}$ 이화여자대학교 화학나노과학과 \\ (2013. 8. 5. 접수, 2013. 8. 29. 수정, 2013. 8. 29. 승인)}

\begin{abstract}
The chemical element and structural characterization of different types of cements and its brick stones are been investigated under forensic aspects using X-ray florescence (XRF) and X-ray diffraction (XRD) spectrometer. The XRF provides rapid compositional data for controlling almost all stages of raw materials, clinker and cement. The decisive advantage of XRD methods is based on the unique character of the diffraction patterns of crystalline substances, the ability to distinguish between elements and their oxides, and the possibility to identify chemical compounds, polymeric forms, and mixed crystals by non-destructive examination. Therefore, combination of these examinations is useful and able to apply for the forensic analysis in comparison of cements and brick stones. There are more study remained to determine the viability of method for forensic analysis of brick stones and the limits of the discrimination that can be achieved.
\end{abstract}

Key words: XRF, XRD, PCA, Cements, Bricks

\section{1. 서 론}

우리주변은 시멘트 원료로 제조된 시멘트 페이스트 (cement pastes; 콘크리트, 모르타르, 벽돌 등)로 건설 된 주택, 빌딩, 도로, 옹벽 등 많은 구조물에 둘러싸여 있다. 그러므로 범행 중 사람과 대상물에 전이된 다양 한 종류의 시멘트가 묻혀진 증거물이 접수 되며 이러 한 시멘트 증거물들은 수사과정에서 증거물들의 가치
와 수사정보를 높이는데 사용될 수 있다. 시멘트 증거 물은 동일성 여부 및 비교 시험뿐 아니라 시멘트의 물리적, 화학적 성분을 분석함으로써 시멘트의 종류와 제조회사에 관한 정보와 출처를 알아내 수사망을 좁 히는데 중요한 역할을 한다. 시멘트는 모래 혹은 자갈 과 함께 물을 혼합하여 고형화를 통한 모래나 자갈을 연결하는 접착제 작용을 한다. 물과 반응하면 C-S-H 겔 $\left(\mathrm{C}_{3} \mathrm{~S}_{2} \mathrm{H}_{8}\right.$, Calcium Silicate Hydrate)이라는 물질을 생

$\star$ Corresponding author

Phone : +82-(0)2-2600-4495 Fax : +82-(0)2-2600-4792

E-mail : minjs@korea.kr 
성하면서 굳어지는 수화반응(hydration)을 거치며 이때 시멘트와 물을 섞어서 만든 것을 시멘트 페이스트 (cement paste)라고 하며, 여기에 잔골재(모래)가 첨가 되면 모르타르(mortar), 그리고 굵은 골재가 더 추가되 면 일반적으로 콘크리트(concrete)라 일컫는다. ${ }^{1}$ 일반 적인 포틀랜트 시멘트의 주성분은 실리카 $\left(\mathrm{SiO}_{2}\right)$, 산화 알루미늄 $\left(\mathrm{Al}_{2} \mathrm{O}_{3}\right)$, 산화철 $\left(\mathrm{Fe}_{2} \mathrm{O}_{3}\right)$, 석회 $(\mathrm{CaO})$ 로 이루어 져 있고 수화반응도 이들 각 성분의 수화반응 특성에 의해서 정해진다. 시멘트의 화학적 조성비를 바꾸면 특정 성질을 가진 조강시멘트, 저발열 시멘트 등을 만 들 수 있다. ${ }^{2}$

법과학적 분석법으로 X-Ray Diffraction (XRD) ${ }^{3,4}$ 과 X-Ray Fluorescence $(\mathrm{XRF})^{5}$ 를 이용하여 시멘트에 함유 된 무기물의 주성분 원소와 내부 미세구조를 종합 분 석하면 시멘트의 종류 및 제조사 구분을 가능하게 하 는 시험방법이 보고되어 있다. ${ }^{6}$ 그러나 실제 여러 제 조사별 종류의 시멘트에 배합되는 첨가물이나 불순물 (혹은 유기물)의 종류가 다양하므로 시멘트 종류를 정 확히 구분해 내기가 어려울 경우가 있다. 본 실험에서 는 가장 시중에 널리 쓰이는 포틀랜드 시멘트 원료에 대한 성분 자료를 기준으로 제조사별 시멘트들과의 성분 비교를 통하여 각각의 특징을 구분 하는 분석 방법을 시도하였다. 또한 시멘트의 주 원료에 대한 분 석 정보를 이미 알고 있거나 제공되어 있는 경우, 증 거물 시멘트 혹은 증거물 벽돌과 비교 분석법을 시도 하여 증거물에 대한 정성분석, 제조 출처에 따른 시기 및 환경에 대한 정보 등을 분석할 수 있는 방법을 모
색해 보았다. 이렇게 분석된 자료들은 데이터 베이스 를 구축하는 토대가 되며 이는 현장의 증거물로 접수 된 시멘트와 관련 증거물들간의 비교 감정에 도움이 되는 결정적 단서가 될 수 있다. 또한 시멘트가 공산 품일 경우, $1 \%$ 이하의 특정 미량물질이 포함되어 있 어 미량원소들에 대한 분석방법은 어떤 물질의 출처 를 알아내거나 그렇지 못할 경우 최소한 항목을 늘릴 수 있는 지표물질로써 사용할 수 있다. 그러므로 시멘 트에 포함된 미량원소에 대한 신속, 정확한 감정기법 의 확립과 더불어 탄소와 수소의 함량 및 안정동위원 소비 및 함량에 대한 정밀한 동정 시험을 통한 원료 의 특성을 연구할 필요성이 요구된다.

\section{2. 재료 및 실험 방법}

\section{1. 시멘트 및 벽돌 제조}

X-Ray 분석기기를 이용하여 분석되는 제조사별 시 멘트와 제조된 벽돌의 종류 및 용도는 다음과 같다 (Table 1과 Table 2). 벽돌(Common Brick)의 제작 공 정은 제조사별로 각각의 종류 시멘트와 모래 그리고 물을 $1: 1: 0.8(\mathrm{v} / \mathrm{v} / \mathrm{v})$ 의 비율로 섞어 저속으로 10 분 동 안 혼합한다. 4 개의 $195 \mathrm{~mL}$ 규격의 종이컵 안에 시 멘트 반죽을 $150 \mathrm{~mL}$ 붓고 압력 없이 상온에서 건조 시킨다. 이 중 시멘트 반죽 1 개는 종이컵 형틀 모양 으로 상온에서 종이컵 없이 굳힌다. 건조는 실외와 일 광에서 자연 건조시키며 열을 이용한 소성과정은 생 략한다.

Table 1. Type of cements

\begin{tabular}{clll}
\hline \hline 제조회사 & $\begin{array}{c}\text { 시멘트 } \\
\text { 데이터 번호 }\end{array}$ & $\begin{array}{c}\text { 제조된 벽돌 } \\
\text { 데이터 번호 }\end{array}$ & 종류 \\
\hline \multirow{2}{*}{ 쌍용양회 } & SSANGYONG-1 & SS-1 & 포틀랜드 시멘트 (1종) \\
& SSANGYONG-2 & 중용열 포틀랜드 시멘트 (2종) & 조강 포틀랜드 시멘트 (3종) \\
& SSANGYONG-3 & SS-3 & 저열 포틀랜드 시멘트 (4종) \\
& SSANGYONG-4 & SS-4 & 초속경 시멘트 \\
& SSANGYONG-5 & SS-5 & 초조강 시멘트 \\
& SSANGYONG-6 & SS-6 소로를래그시멘트(슬래그 시멘트) \\
& SSANGYONG-7 & SS-7 & 저발열 시멘트 (조강형 저발열) \\
\hline \multirow{2}{*}{ 동양 } & SSANGYONG-8 & SS-8 & 동양시멘트 1종 \\
(DONGYANG) & DONGYANG-1 & DY-1 & 동양시멘트 3종 \\
& DONGYANG-2 & DY-2 & 동양시멘트 4종 \\
\hline \multirow{2}{*}{ 한라라파즈 } & DONGYANG-3 & DY-3 & 포틀랜드 시멘트 1종 \\
(HANRA) & HANRA-1 & HR-1 & 저발열 시멘트 4종 \\
& HANRA-2 & HR-2 & 고로슬래그 시멘트 \\
\hline
\end{tabular}


Table 2. The Characteristic and Purposes of cements ${ }^{4}$

\begin{tabular}{|c|c|c|}
\hline 구분 & 특성 & 용도 \\
\hline $\begin{array}{l}1 \text { 종 } \\
\text { (보통) }\end{array}$ & - 콘크리트 공사용으로 가장 많이 사용되고 있는 시멘트로 & 룩내에서 생산되는 시멘트의 대부분을 차지 \\
\hline $\begin{array}{c}2 \text { 종 } \\
\text { (중용열) }\end{array}$ & $\begin{array}{l}\text { - 장기강도를 발현하는 } 2 \mathrm{CaO} \cdot \mathrm{SiO}_{2} \text { 를 최대화해 수화과 } \\
\text { 정에서 초기 수화 열을 낮추고 투수 저항성을 높임 }\end{array}$ & $\begin{array}{l}\text { - 큰 체적의 콘크리트 구조물 (댐 공사) } \\
\text { - 도로보수용 콘크리트 }\end{array}$ \\
\hline $\begin{array}{c}\text { 3종 } \\
\text { (조강) }\end{array}$ & $\begin{array}{l}\text { - 단기강도가 셈 (조강시멘트 재령 } 1 \text { 일의 강도가 포틀랜 } \\
\text { 드 시멘트의 재령 } 3 \text { 일 강도와 거의 같음) }\end{array}$ & $\begin{array}{l}\text { - 도로 및 수중공사 등 긴급공사 } \\
\text { - 콘크리트 공사에서 공기를 단축하기 위해 사용 }\end{array}$ \\
\hline $\begin{array}{c}4 \text { 종 } \\
\text { (저열) }\end{array}$ & -2 종 중용열 시멘트보다 $2 \mathrm{CaO} \mathrm{SiO}_{2}$ 의 함량을 더 높임 & $\begin{array}{l}\text { - 2종과 유사 용도 } \\
\text { - 대규모 매스콘크리트 (지하철, 공항 공사) }\end{array}$ \\
\hline
\end{tabular}

\subsection{X-ray fluorescence spectrometer를 이용한 화학조성 분석}

$\mathrm{XRF}$ 를 이용하여 주 구성 원소들의 분석을 위해 사 용된 시멘트와 제조된 벽돌은 약 $500 \mu \mathrm{m}$ 크기로 갈 아 분쇄하였으며 균질성을 향상시키기 위하여 일정량 을 취하여 펠릿과 비드형태로 만들었다. 펠릿은 $2 \mathrm{~g}$ 을 취하여 SPEX SamplePrep 3635 X-Press (SPEX Sample Prep Group, 미국)를 이용하여 직경 $13 \mathrm{~mm}$ 의 원판형 태의 펠렛을 만들었다. 비드 제작에 사용된 장비는 $\mathrm{K} 2$ Prime (Katanax, 캐나다)이며, 분쇄된 시료 $0.5 \mathrm{~g}$ 에 리튬 사보레이트(Lithium Tetraborate) $4.5 \mathrm{~g}$ 과 박리제 브롬화리튬(Lithiumbromide) $0.03 \mathrm{~g}$ 을 첨가하여 1200 ${ }^{\circ} \mathrm{C}$ 하에서 직경 $30 \mathrm{~mm}$ 의 비드를 제작하였다. $\mathrm{XRF}$ 장 비는 M4 TORNADO (Bruker, 독일)를 사용하였으며 각 시료는 5 회 이상 측정하였다.

\subsection{X-ray diffraction spectrometer를 이용한 성분 분석}

제조사별 종류의 시멘트와 제조된 벽돌은 $8000 \mathrm{D}$ Mixer/Mill (SPEX Sample Prep, 미국)을 이용하여 분 쇄한 후 분석하였다. XRD는 $\mathrm{D} 8 \mathrm{ADVANCE} \mathrm{X}$ 선 회 절분석기 (Bruker, 독일)를 사용하였으며 각각의 시료 는 5 회 분석하였다. 데이터는 DIFFRAC.SUITE. EVA Software로 스펙트럼을 분석하고 Data library 이용하 여 분석된 스펙트럼과 일치하는 성분을 찾아낸다.

\section{4. 다변량 통계분석법(Principal Components Analysis)}

제조사별 시멘트와 각각의 시멘트 원료로 제조된 벽돌은 모든 시험에서 5 회 이상 측정 후 얻어진 평 균값을 사용하여 다변량 통계 분석기법인 주성분 분 석 $(\mathrm{PCA})$ 을 실시하였다. ${ }^{7,8}$ 주성분 분석을 통하여 얻어 진 전체 데이터의 패턴을 조사한 후 주성분을 기준으 로 데이터를 분류하여 시멘트 원료와 벽돌의 종류를
구분하였다. SIMCA-P ${ }^{+}$Version 12.0 (Umetrics, 미국) Software을 사용하여 분석하였으며 신뢰수준은 모두 $95 \%$ 에서 진행되었다.

\section{3. 결과 및 고찰}

\section{1. 제조사별 시멘트 원료의 분석 및 분류}

시중에서 판매되고 있는 3 사의 제조 업체 중 (쌍용 양회 8 종, 동양 3 종, 한라라파즈 3 종) 총 14 종의 시멘트 원료를 XRD를 이용하여 분석하였다. 각각의 시멘트 결정의 회절각과 강도는 물질 구조의 고유한 성질로 $\mathrm{X}$ 선을 시멘트 결정에 부딪혀 이 회절 $\mathrm{X}$ 선을 분석하여 시료에 함유된 결정성 물질의 구조 및 종류 와 양에 관계되는 정보를 알 수 있다. XRD 분석에 사용되는 제조사별 시멘트의 종류 및 용도는 재료 및 실험방법 2.1에 설명하였다(Table 1과 Table 2). 또한 시멘트 주요 무기물 성분 원소는 XRF를 이용하여 분 석할 수 있는데 X-선을 물질에 조사하여 발생되는 형 광 $\mathrm{X}$ 선을 검출하여 원소의 종류를 밝혀낼 수 있다. 본 연구에서 수행되는 3 사의 시멘트 원료 중 쌍용과 동양의 시멘트의 성분원소 분석결과를 각 제조사에서 분석한 결과값과 비교하였으며 이들의 분석 데이터 결과 공통 성분원소는 $\mathrm{MgO}, \mathrm{Al}_{2} \mathrm{O}_{3}, \mathrm{SiO}_{2}, \mathrm{SO}_{3}, \mathrm{~K}_{2} \mathrm{O}$, $\mathrm{CaO}, \mathrm{MnO}, \mathrm{Fe}_{2} \mathrm{O}_{3}, \mathrm{TiO}_{2}, \mathrm{Na}_{2} \mathrm{O}, \mathrm{P}_{2} \mathrm{O}_{5}$ 이다(Table 3). 시멘트 원료를 분석하기 위하여 시료는 강한 압축으 로 성형한 펠릿(Pellet) 형태와 열을 가하여 제조한 비 드(Bead) 형태의 두 가지로 제작하였으며 시료들 모 두 각 제조사에서 제공한 데이터와 동일한 성분이 분 석되었다. 다만 시료 제조 형태에 따라 시멘트의 분석 함량이 다르므로 제조사에서 제공된 데이터 값과 비 교하면 펠릿 형태로 제조한 시멘트의 화학성분 함량 이 비드 형태 시멘트 보다 더 근접한 값을 보인다. 비 드 형태의 시멘트는 오차허용 범위를 고려하더라도 제조사에서 제공된 데이터 값보다 성분 함량이 크게 
Table 3. Comparison of cement manufacturer data and experimental data for chemical properties

\begin{tabular}{|c|c|c|c|c|c|c|c|c|c|c|c|}
\hline \multirow{2}{*}{ 구분 } & \multicolumn{11}{|c|}{$\mathrm{XRD}$ 분석 화학성분(\%), ( } \\
\hline & $\mathrm{MgO}$ & $\mathrm{Al}_{2} \mathrm{O}_{3}$ & $\mathrm{SiO}_{2}$ & $\mathrm{SO}_{3}$ & $\mathrm{~K}_{2} \mathrm{O}$ & $\mathrm{CaO}$ & $\mathrm{MnO}$ & $\mathrm{Fe}_{2} \mathrm{O}_{3}$ & $\mathrm{TiO}_{2}$ & $\mathrm{Na}_{2} \mathrm{O}$ & $\mathrm{P}_{2} \mathrm{O}_{5}$ \\
\hline 쌍용-1 & $\begin{array}{l}1.36 \\
(3.6)\end{array}$ & $\begin{array}{l}3.19 \\
(5.2)\end{array}$ & $\begin{array}{l}55.63 \\
(19.8)\end{array}$ & $\begin{array}{l}1.42 \\
(2.3)\end{array}$ & $\begin{array}{c}2.44 \\
(0.92)\end{array}$ & $\begin{array}{l}28.14 \\
(62.0)\end{array}$ & $\begin{array}{c}0.11 \\
(0.19)\end{array}$ & $\begin{array}{l}2.09 \\
(2.9)\end{array}$ & $\begin{array}{c}0.60 \\
(0.18)\end{array}$ & $\begin{array}{c}1.35 \\
(0.17)\end{array}$ & $\begin{array}{c}0.04 \\
(0.30)\end{array}$ \\
\hline 쌍용-2 & $\begin{array}{l}0.75 \\
(2.3)\end{array}$ & $\begin{array}{l}7.16 \\
(3.6)\end{array}$ & $\begin{array}{l}31.47 \\
(22.8)\end{array}$ & $\begin{array}{l}1.24 \\
(2.0)\end{array}$ & $\begin{array}{c}3.14 \\
(0.98)\end{array}$ & $\begin{array}{l}24.90 \\
(62.4)\end{array}$ & $\begin{array}{c}0.10 \\
(0.12)\end{array}$ & $\begin{array}{c}1.97 \\
(3.4)\end{array}$ & $\begin{array}{c}0.19 \\
(0.13)\end{array}$ & $\begin{array}{c}1.41 \\
(0.13)\end{array}$ & $\begin{array}{c}0.03 \\
(0.20)\end{array}$ \\
\hline 쌍용-3 & $\begin{array}{l}0.95 \\
(3.0)\end{array}$ & $\begin{array}{l}6.10 \\
(4.6)\end{array}$ & $\begin{array}{l}32.36 \\
(20.5)\end{array}$ & $\begin{array}{l}1.72 \\
(3.6)\end{array}$ & $\begin{array}{c}2.65 \\
(1.30)\end{array}$ & $\begin{array}{l}23.81 \\
(62.8)\end{array}$ & $\begin{array}{c}0.09 \\
(0.13)\end{array}$ & $\begin{array}{l}1.94 \\
(3.2)\end{array}$ & $\begin{array}{c}0.18 \\
(0.15)\end{array}$ & $\begin{array}{c}1.75 \\
(0.13)\end{array}$ & $\begin{array}{c}0.03 \\
(0.26)\end{array}$ \\
\hline 쌍용-4 & $\begin{array}{l}0.54 \\
(1.7)\end{array}$ & $\begin{array}{l}5.87 \\
(2.8)\end{array}$ & $\begin{array}{l}32.75 \\
(24.8)\end{array}$ & $\begin{array}{l}1.08 \\
(1.9)\end{array}$ & $\begin{array}{c}2.31 \\
(0.57)\end{array}$ & $\begin{array}{l}24.97 \\
(62.7)\end{array}$ & $\begin{array}{c}0.09 \\
(0.08)\end{array}$ & $\begin{array}{l}1.91 \\
(3.4)\end{array}$ & $\begin{array}{c}0.14 \\
(0.09)\end{array}$ & $\begin{array}{c}1.56 \\
(0.10)\end{array}$ & $\begin{array}{c}0.02 \\
(0.17)\end{array}$ \\
\hline 쌍용-5 & $\begin{array}{l}0.55 \\
(1.4)\end{array}$ & $\begin{array}{l}11.95 \\
(14.7)\end{array}$ & $\begin{array}{l}26.05 \\
(13.7)\end{array}$ & $\begin{array}{c}7.92 \\
(14.2)\end{array}$ & $\begin{array}{c}2.30 \\
(0.36)\end{array}$ & $\begin{array}{l}23.84 \\
(49.5)\end{array}$ & $\begin{array}{c}0.12 \\
(0.07)\end{array}$ & $\begin{array}{l}2.03 \\
(2.4)\end{array}$ & $\begin{array}{c}0.40 \\
(0.17)\end{array}$ & $\begin{array}{c}1.93 \\
(0.26)\end{array}$ & $\begin{array}{c}0.04 \\
(0.52)\end{array}$ \\
\hline 쌍용-6 & $\begin{array}{l}1.18 \\
(3.1)\end{array}$ & $\begin{array}{l}6.15 \\
(5.3)\end{array}$ & $\begin{array}{l}31.91 \\
(19.4)\end{array}$ & $\begin{array}{l}2.19 \\
(4.5)\end{array}$ & $\begin{array}{c}2.35 \\
(0.87)\end{array}$ & $\begin{array}{l}24.17 \\
(61.4)\end{array}$ & $\begin{array}{c}0.21 \\
(0.17)\end{array}$ & $\begin{array}{l}1.98 \\
(2.8)\end{array}$ & $\begin{array}{c}0.63 \\
(0.14)\end{array}$ & $\begin{array}{c}1.18 \\
(0.10)\end{array}$ & $\begin{array}{c}0.03 \\
(0.24)\end{array}$ \\
\hline 쌍용-7 & $\begin{array}{l}1.57 \\
(3.9)\end{array}$ & $\begin{array}{c}4.23 \\
(10.3)\end{array}$ & $\begin{array}{l}55.95 \\
(25.7)\end{array}$ & $\begin{array}{l}2.11 \\
(2.6)\end{array}$ & $\begin{array}{c}2.50 \\
(0.56)\end{array}$ & $\begin{array}{l}25.12 \\
(52.5)\end{array}$ & $\begin{array}{c}0.14 \\
(0.24)\end{array}$ & $\begin{array}{l}1.69 \\
(2.0)\end{array}$ & $\begin{array}{c}0.30 \\
(0.44)\end{array}$ & $\begin{array}{c}1.61 \\
(0.24)\end{array}$ & $\begin{array}{c}0.03 \\
(0.09)\end{array}$ \\
\hline 쌍용-8 & $\begin{array}{l}1.07 \\
(3.3)\end{array}$ & $\begin{array}{c}4.69 \\
(12.1)\end{array}$ & $\begin{array}{l}62.00 \\
(30.5)\end{array}$ & $\begin{array}{l}2.56 \\
(4.2)\end{array}$ & $\begin{array}{c}3.00 \\
(0.55)\end{array}$ & $\begin{array}{l}17.30 \\
(42.4)\end{array}$ & $\begin{array}{c}0.12 \\
(0.21)\end{array}$ & $\begin{array}{l}2.18 \\
(3.6)\end{array}$ & $\begin{array}{c}0.58 \\
(0.62)\end{array}$ & $\begin{array}{c}1.20 \\
(0.30)\end{array}$ & $\begin{array}{c}0.02 \\
(0.12)\end{array}$ \\
\hline 동양-1 & $\begin{array}{c}2.63 \\
(2.92)\end{array}$ & $\begin{array}{c}2.40 \\
(5.55)\end{array}$ & $\begin{array}{l}20.02 \\
(21.5)\end{array}$ & $\begin{array}{c}4.41 \\
(2.44)\end{array}$ & $\begin{array}{c}1.18 \\
(1.15)\end{array}$ & $\begin{array}{l}61.50 \\
(60.8)\end{array}$ & 0.14 & $\begin{array}{c}3.67 \\
(3.83)\end{array}$ & 0.35 & $\begin{array}{c}0.84 \\
(0.10)\end{array}$ & 0.14 \\
\hline 동양-2 & $\begin{array}{c}2.80 \\
(0.01)\end{array}$ & $\begin{array}{c}2.13 \\
(5.19)\end{array}$ & $\begin{array}{c}18.91 \\
(20.58)\end{array}$ & $\begin{array}{c}3.76 \\
(3.07)\end{array}$ & $\begin{array}{c}0.84 \\
(0.89)\end{array}$ & $\begin{array}{l}64.20 \\
(62.7)\end{array}$ & 0.14 & $\begin{array}{c}3.50 \\
(3.58)\end{array}$ & 0.33 & $\begin{array}{c}0.87 \\
(0.11)\end{array}$ & 0.13 \\
\hline 동양-3 & $\begin{array}{c}3.92 \\
(3.52)\end{array}$ & $\begin{array}{l}1.64 \\
(3.3)\end{array}$ & $\begin{array}{c}21.33 \\
(23.33)\end{array}$ & $\begin{array}{l}3.52 \\
(2.1)\end{array}$ & $\begin{array}{c}0.62 \\
(0.12)\end{array}$ & $\begin{array}{l}62.73 \\
(60.1)\end{array}$ & 0.15 & $\begin{array}{c}3.29 \\
(3.42)\end{array}$ & 0.22 & $\begin{array}{c}0.68 \\
(0.79)\end{array}$ & 0.03 \\
\hline
\end{tabular}

측정되었다. 따라서 본 실험에서는 펠릿으로 제조된 원료 시료를 분석에 사용하였으며 3 사 모두 주성분으 로는 $\mathrm{CaO}, \mathrm{SiO}_{2}$ 이며 $10 \%$ 미만 함량의 $\mathrm{Al}_{2} \mathrm{O}_{3}, \mathrm{SO}_{3}$, $\mathrm{Fe}_{2} \mathrm{O}_{3}$ 와 미량의 나머지 화학성분으로 나타냈다(Fig. 1).

시멘트들을 제조사 별로 분석한 결과 동일 화학성 분이 분석되며 특정 성분을 통한 시멘트 종류의 분류 및 식별은 어려워 성분함량 비율에 따른 분석법에 접 근을 시도하였다. 제조사별 시멘트 원료를 5 회 분석 한 XRF 데이터들을 통계학적 주성분 분석 $\mathrm{PCA}$ (Principal Component Analysis)법을 수행하였다. 통계 학적 주성분 분석은 각각의 축에 데이터의 '가장 중요 한' 성분을 위치시킴으로써 시멘트의 성분 분석 함량 에 따른 종류를 분류할 수 있는 방법이 된다. ${ }^{7,8}$ 본 실 험에서 $\mathrm{XRF}$ 평균 함량 값이 $30 \%$ 이상인 $\mathrm{CaO}$ 와 $\mathrm{SiO}_{2}$ 를 기준으로 시멘트 종류를 나누어 보면 크게 두 분류로 나뉘어진다. Fig. 2(a)에서 큰 원형 안에 위치 하는 쌍용 5 종을 제외한 나머지 쌍용 7 종(1종 4종, 6 종 8종) 그리고 각 3 종의 동양과 한라의 시멘트들이 Type 1로 분류되고 쌍용 초속경 5종(SS-5)은 Type 2 로 분류된다. Type 2의 초속경 시멘트는 Type 1의 시 멘트들과 비교하여 $\mathrm{CaO}$ 와 $\mathrm{SiO}_{2}$ 가 상대적으로 함량이
매우 낮고 $\mathrm{SO}_{3}$ 의 함량이 높아 초속경 시멘트를 구별 하는 주요 화학성분이 될 수 있다. $\mathrm{CaO}$ 와 $\mathrm{SiO}_{2}$ 의 함 량을 기준으로 Type 1의 시멘트들을 좀 더 세부적으 로 분류해보면, 저발열 시멘트(쌍용 7 종, 한라의 3 종) 를 Type 1'으로 고로슬래그 시멘트(쌍용 8 종, 한라 2 종)를 Type 1"으로 분류하고 그 밖의 나머지 시멘트 들로 세분화 분류가 가능하다. 특히 함량 값이 $15 \%$ 미만인 미량성분 원소들 $\mathrm{Al}_{2} \mathrm{O}_{3}, \mathrm{Fe}_{2} \mathrm{O}_{3}, \mathrm{Na}_{2} \mathrm{O}, \mathrm{MgO}$, $\mathrm{SO}_{3}$ 의 통합 함량을 기준으로 살펴보면 저발열 시멘트 와 고로슬래그 시멘트가 더욱 분명하게 분류되며 $\mathrm{Al}_{2} \mathrm{O}_{3}$ 와 $\mathrm{Fe}_{2} \mathrm{O}_{3}$ 의 함량은 저발열 시멘트가 많고 $\mathrm{Na}_{2} \mathrm{O}_{3}$ 의 함량은 고로슬래그 시멘트에 적게 함유되어 있어 고로슬래그 시멘트만의 특징적 성분으로 고려될 수 있다 (Fig. 2(b)).

시멘트 원료의 성분함량 분석만으로는 제조사별 시 멘트 종류의 구별이 쉽지 않으므로 분석의 정확성과 정밀성을 향상시키기 위하여 물질의 고유한 회절 패 턴을 $\mathrm{XRD}$ 와 $\mathrm{XRF}$ 를 이용한 종합 분석을 시도하였다. $\mathrm{XRD}$ 비교 분석 결과 제조사별 시멘트의 $\mathrm{X}$ 선 회절 패턴은 4 가지 타입으로 분류된다. 쌍용 포틀랜드 시 멘트 1, 2, 4 종과 동양, 한라의 시멘트는 Type A로 

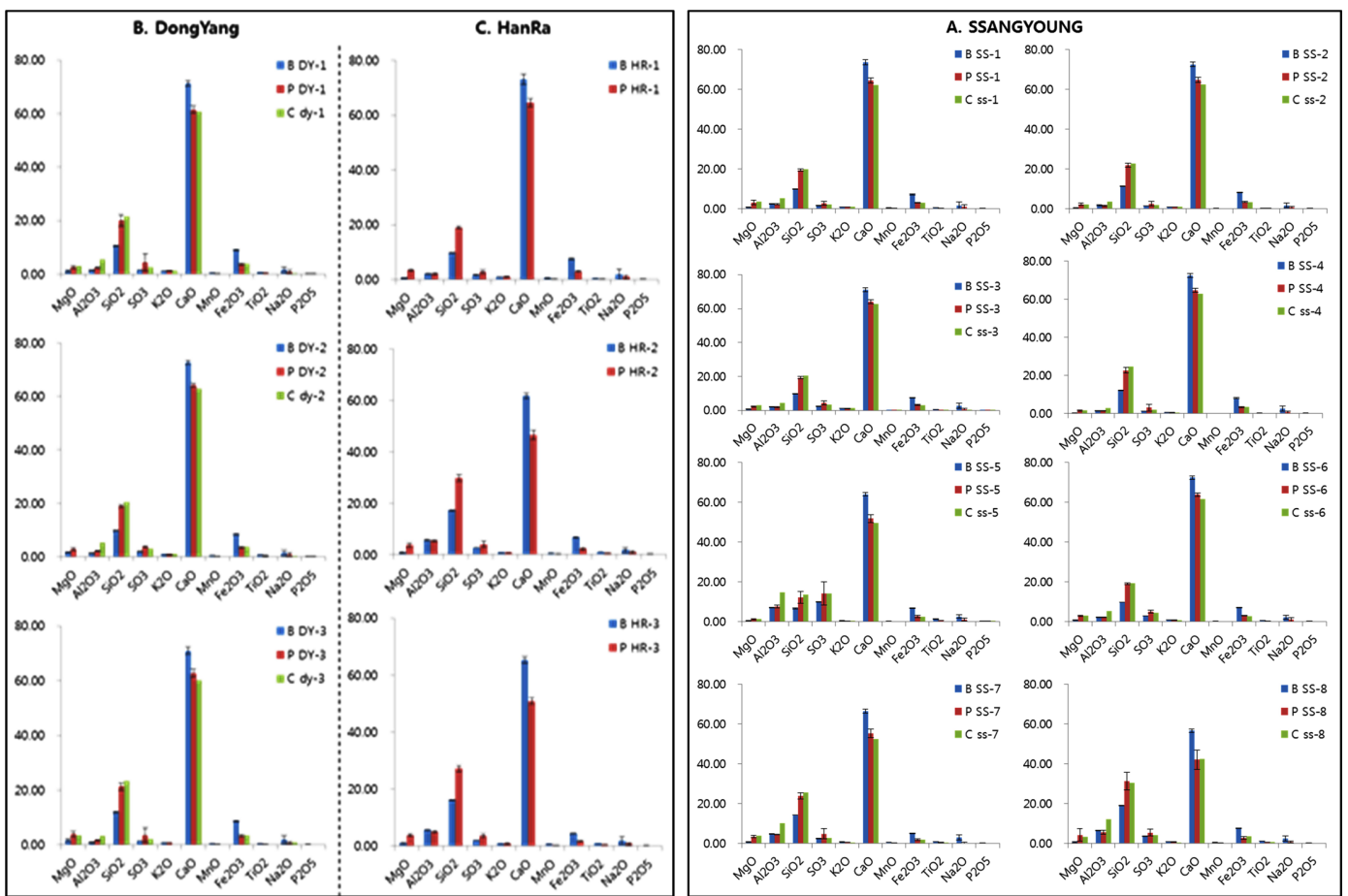

Fig. 1. The chemical composition of cement pellets and beads by XRF analysis. The comparison of product manufacturer data with experimental data shows that the chemical amount of cement pellets has come closer than cement beads data to the cement manufacturer data.

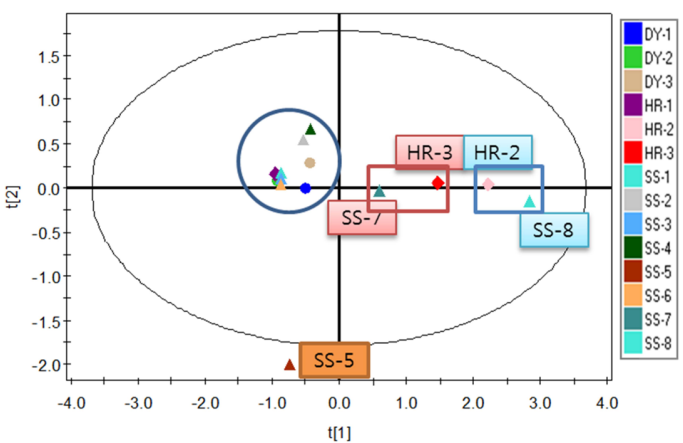

(a)

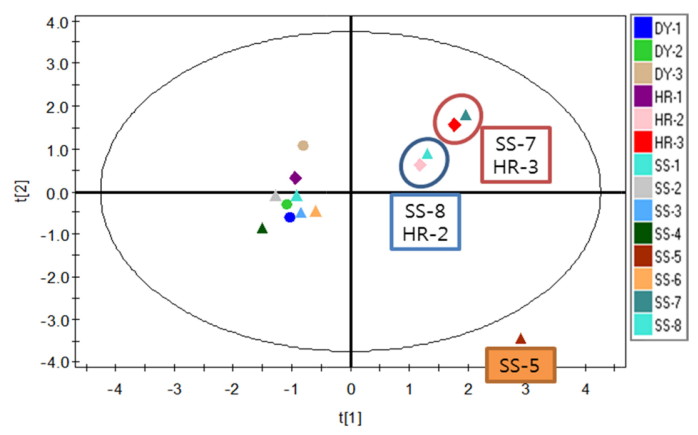

(b)

Fig. 2. (a) The PCA-X calculation graph of cements. Two groups were divided in a SS-5 cement and the other cement according to amount of $\mathrm{CaO}$ and $\mathrm{SiO}_{2}$. These group were computed, giving the performance indicators $\mathrm{R}^{2} \mathrm{X}[1]=0.369, \mathrm{R}^{2} \mathrm{X}[2]=$ $0.174 \mathrm{R}^{2} \mathrm{X}[1]=0.810 \mathrm{R}^{2} \mathrm{X}[2]=0.189$. The $\mathrm{R}^{2}$ values for five individual variables are plotted in Fig. 2(a), (b) The Low heat of hydration blended cement (Type 1') and Portland blast-furnace slag cement (Type 1") were separated by properties of trace chemical elements $\left(\mathrm{Al}_{2} \mathrm{O}_{3}, \mathrm{Fe}_{2} \mathrm{O}_{3}, \mathrm{Na}_{2} \mathrm{O}, \mathrm{MgO}, \mathrm{SO}_{3}\right)$.

분류되고 쌍용 $3,6,7$ 종은 Type $\mathrm{B}$, 쌍용 5 종은 Type $\mathrm{C}$, 쌍용 8 종은 Type $\mathrm{D}$ 로 분류된다(Fig. 3). XRF로 분석된 시멘트 2 가지 타입(Type 1, Type 2)과 XRD 분석된 시멘트 4 가지 타입(Type A Type D)을 비교해 보면 초속경 시멘트인 Type 2 는 Type C 와 구조와 성
분함량이 동일하며 Type 1 (Type 1'과 Type 1" 포함)은 Type A, Type B, Type D와 동일하다. 즉, Type 1의 시멘트들은 $\mathrm{XRD}$ 를 이용하여 구조패턴을 분석할 경우 Type A, B, D로 세부적으로 분류가 가능함을 의미하 며 XRF 분류 결과와 함께 통합 분석하면 쌍용의 시 


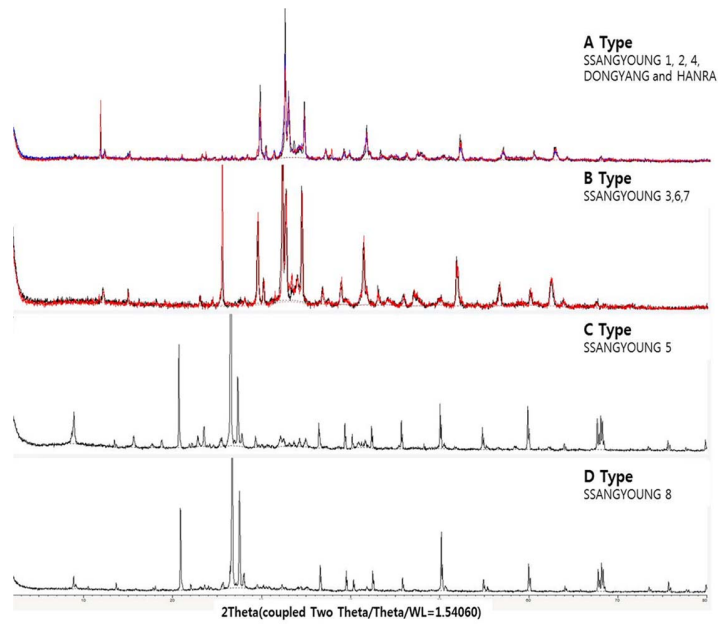

Fig. 3. XRD reveals highly detailed information about theminerlogical composition and crystallographic structure of materials. Four types of XRD spectra for cement pellets according to product manufacturer; A Type: SSANGYONG-1, -2, -4, DONGYANG-1, -2, -3 and HANRA-1, -2, -3, B Type: SSANGYONG-3, -6, -7, C Type: SSANGYONG-5 and D Type: SSANGYONG-8.
멘트들의 세부 분류가 가능하며 Type 1'은 Type B의 고로슬래그로 Type 1"은 Type D의 저발열 시멘트로 분류된다.

포틀랜드 시멘트(Portlandite cement)는 일반적인 시 멘트 (Ordinary cement)라 해도 지장이 없을 만큼 많 이 보급되어 있는 시멘트이므로 포틀랜드 시멘트 1종 의 $\mathrm{X}$ 선 회절 패턴을 기준으로 하여 다른 종류의 시멘 트 스펙트럼과의 비교 분석을 수행하여 시멘트 종류 의 구별이 가능하였다. Type $\mathrm{A}$ 의 쌍용 시멘트들은 $\mathrm{XRD}$ 의 $2 \theta$ 값이 28 과 35 사이에 Main peak들이 존재 하며 주요 스펙트럼 성분은 Portlandite이었다. XRD 라이브러리에서 제공된 Ordinary Portlandite의 스펙트럼 과 비교하여 보았을 때 20값 11.71에서 강한 Intensity가 관찰되며 이것은 Calcium Aluminium Oxide Hydrate가 주요 성분 Peak로 관찰된다(Fig. 4(a)). 또한 동양과 한 라의 시멘트도 Type A와 동일한 스펙트럼 양상이었다. Type B의 시멘트들도 Type A와 유사한 스펙트럼을 패 턴을 보이나 $2 \theta$ 값 25.51에서 Type A와 다른 Peak가

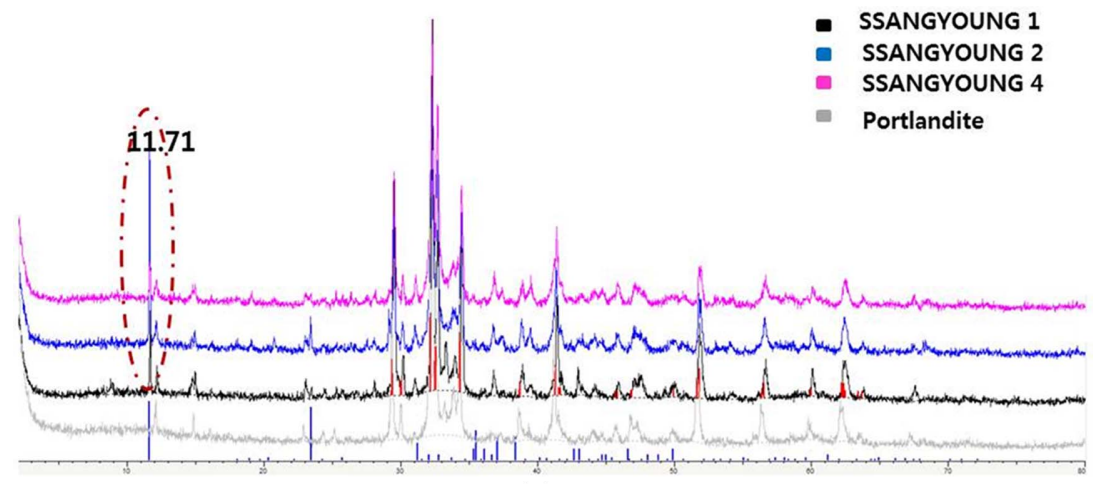

(a)

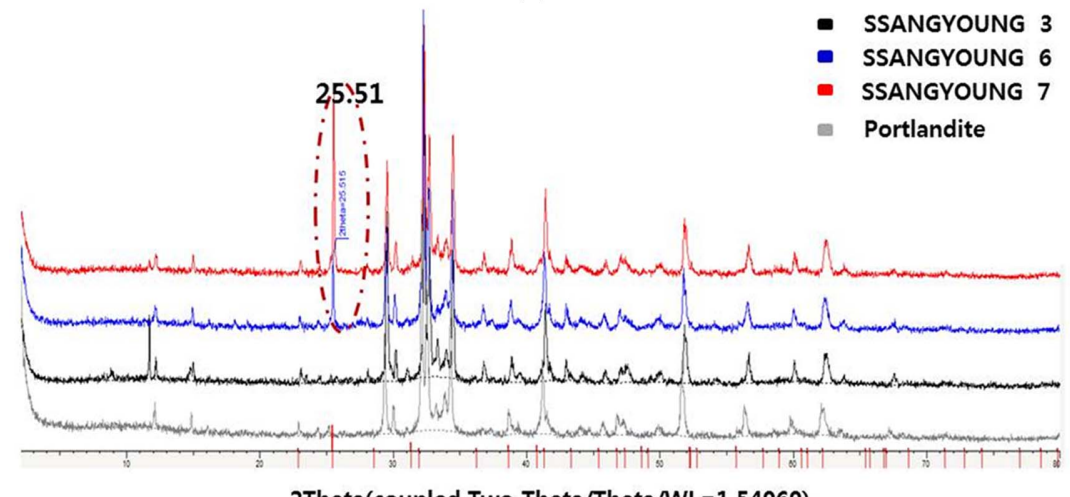

2Theta(coupled Two Theta/Theta/ WL $=1.54060$ )

(b)

Fig. 4. (a) and (b) Comparison of SSANGYOUNG cements (Type A, Type B) and portlandite by XRD spectrometer, (c) and (d) Comparison of SSANGYOUNG-5 and -8 cements by XRD spectrometer. 


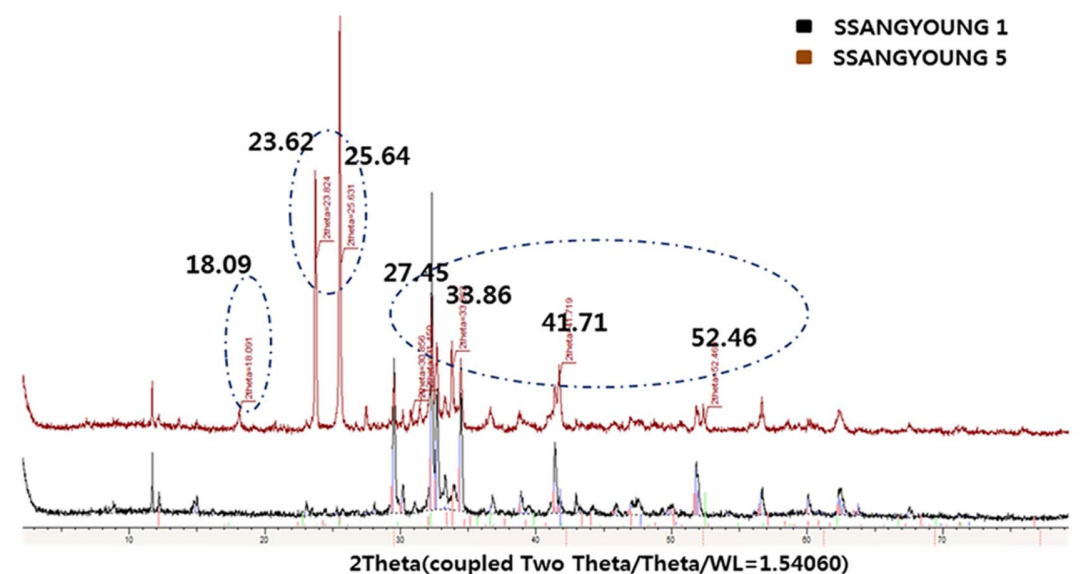

(c)

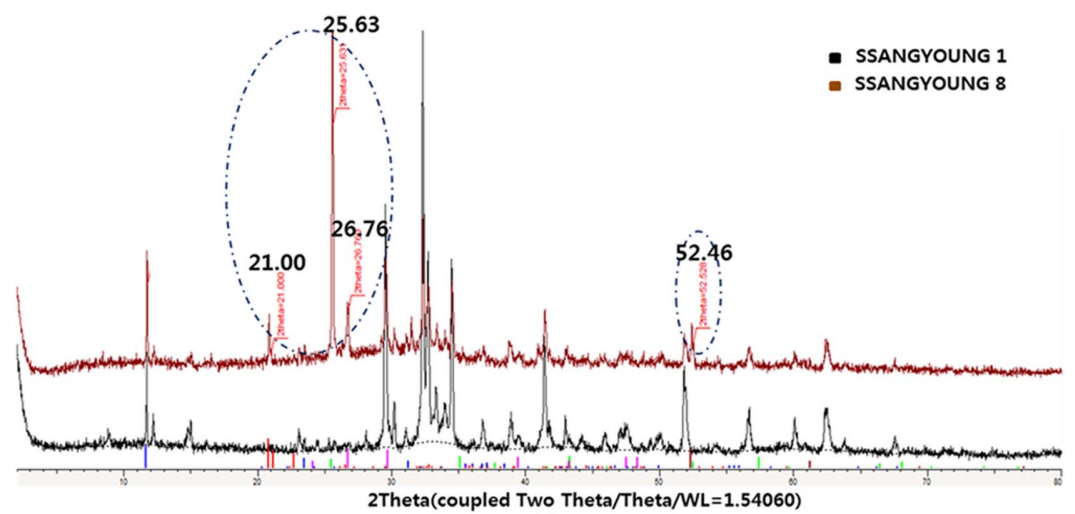

(d)

Fig. 4. Continued.

보이고 주성분으로 Anhydrite $\left(\mathrm{CaSO}_{4}\right)$ 가 검출되었다 (Fig. 4(b)).

쌍용 초속경 시멘트(Type C)와 한라 저발열 시멘트 (Type D)는 $2 \theta$ 값이 20 과 30 사이에서 주요 peak들 이 관찰되는 유사한 스펙트럼 패턴을 보이며 Type $\mathrm{A}$ 의 스펙트럼과는 다른 특징이 보였다. Type $\mathrm{C}$ 는 $2 \theta$ 의 주요 화학성분 값이 $18.09\left(\mathrm{Ca}(\mathrm{OH})_{2}\right), 23.62$ (Ye'elimite, $\left.\left(\mathrm{Ca}_{3} \mathrm{Al}_{6} \mathrm{O}_{12} \cdot \mathrm{CaSO}_{4}\right)\right), 25.64$ (Calcium Sulfate, $\left.\mathrm{CaSO}_{4}\right), 27.45$ (Calcite, $\left.\left(\mathrm{CaCO}_{3}\right)\right), 33.86$ (Brownmillerite, $\mathrm{Ca}\left(\mathrm{AlFe}^{3+}\right)_{2} \mathrm{O}_{5}$ ), 41.71, 52.46 (Forsterite, $\mathrm{Mg}_{2} \mathrm{SiO}_{4}$ )로 확인되고 Type $\mathrm{D}$ 스펙트럼은 $2 \theta$ 값이 21.00 (Rostite, $\mathrm{Al}\left(\mathrm{SO}_{4}\right)(\mathrm{OH}) \cdot 5 \mathrm{H}_{2} \mathrm{O}$ ), 25.63 (Aluminum Oxide, $\mathrm{Al}_{2} \mathrm{O}_{3}$ ), 26.76 (Calcium Oxide, $\mathrm{CaO}$ )에서 Type $\mathrm{A}$ 와 구별되는 스팩트럼 패턴이 분석된다(Fig. 4(c), Fig. 4(d)). 따라서 제조사별 시멘트는 XRD를 이용하 여 일반적인 포틀랜드 시멘트와 겹치지 않는 특정 부
분 영역의 스펙트럼을 비교하고 찾아냄으로써 시멘트 의 분류 및 분석이 가능하였다.

\section{2. 제조사별 벽돌의 분석 및 분류}

일반적으로 시멘트 페이스트(Cement Paste; 모르타 르, 콘크리트, 벽돌 등)는 혼재된 생태이므로 편광현미 경으로 관찰하기 어려운 경우가 많아 X-Ray 회절법에 의한 검출이 유효하다. 제조사별 각 종류의 시멘트와 물과 모래를 혼합하고 반죽하여 제작된 다섯 개의 벽 돌(Brick stone)을 만든 후 벽돌을 분쇄하여 X-Ray 회 절기(XRD)로 분석 한 결과는 다음과 같다. Type $\mathrm{A}$ 의 포틀랜드 시멘트로 만든 벽돌(SS-1)의 기본 조성을 살 펴보면 알라이트라고 하는 규산삼칼슘 $\left(3 \mathrm{CaO} \cdot \mathrm{SiO}_{2}\right)$ 계 화합물, 벨라이트라고 하는 규산이칼슘 $\left(2 \mathrm{CaO} \cdot \mathrm{SiO}_{2}\right)$ 계 화합물, 알루민산칼슘 $\left(3 \mathrm{CaO} \cdot \mathrm{Al}_{2} \mathrm{O}_{3}\right)$ 계 화합물, 알루미 노아철산칼슘 $\left(4 \mathrm{CaO} \cdot \mathrm{Al}_{2} \mathrm{O}_{3} \cdot \mathrm{Fe}_{2} \mathrm{O}_{3}\right)$ 계 화합물 및 석고 


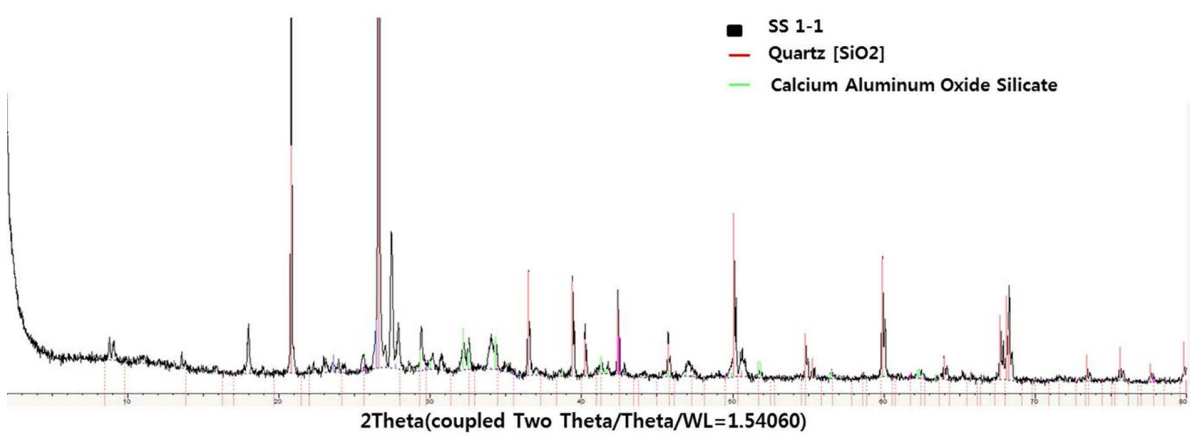

Fig. 5. Spectrum of Portlandite Brick (SS-1) by XRD analysis. Portland brick (often known simply as cement brick) is created by mixing ordinary portland cement and sand with water and those chemical elements were measured in XRD.

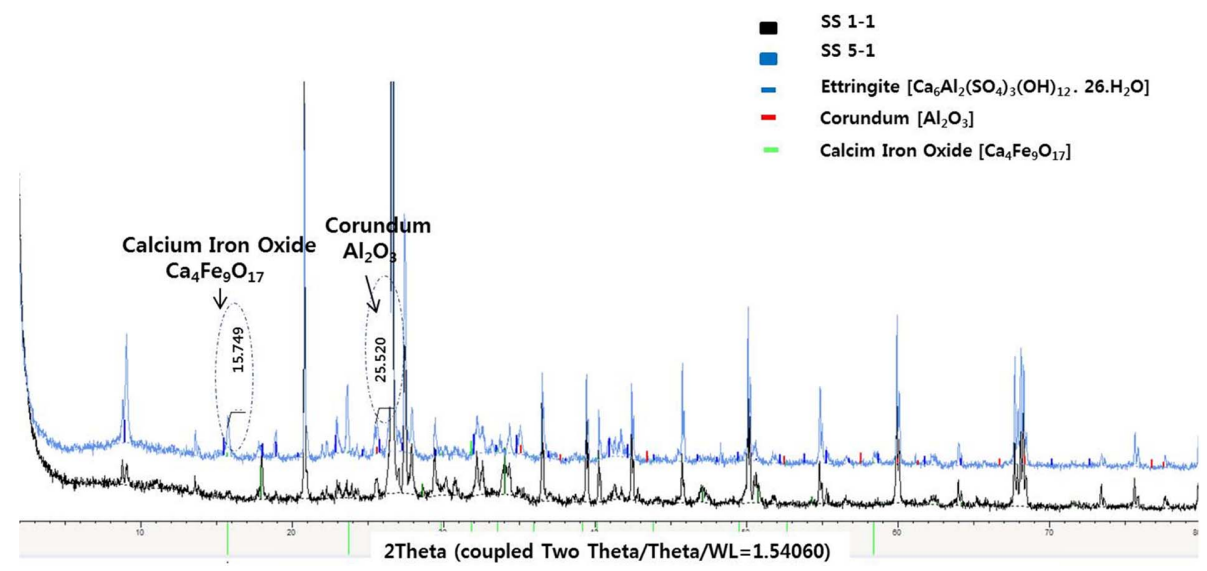

Fig. 6. Comparison of bricks between SS-1 and SS-5. The SS-5 data indicates that $2 \theta$ values 15.75 and 25.52 are corresponding to Calcium Iron Oxide and Corundum in XRD spectra.

$\left(\mathrm{CaSO}_{4} \cdot 2 \mathrm{H}_{2} \mathrm{O}\right)$ 의 5 종류 화합물로 분석되었고 시멘트 주성분인 Portlandite 이외에 모래의 주 성분인 Quartz $\left(\mathrm{SiO}_{2}\right)$ 와 Calcium Hydroxide, Calcium Magnesium Aluminum Oxide Silicate와 소량의 석회가 분석된다 (Fig. 5).

쌍용 시멘트로 제조한 8종류의 벽돌을 (SS-1 SS-8) 비교 분석하면, 초속경 시멘트로 제조한 벽돌을 제외한 다른 7 종류의 벽돌은 건조 방식과 상관없이 동일한 스팩트럼 양상으로 관찰되었다. 초속경 시멘트 (SS-5) 는 보통 포틀랜드 시멘트에 존재하지 않는 수화활성도 가 높고 안정한 수화물을 생성시키는 $3 \mathrm{CaO} \cdot 3 \mathrm{Al}_{2} \mathrm{O}_{3}$. $\mathrm{CaSO}_{4}$ 을 다량 함유하고 있어 수화반응시 매우 빠른 속 도로 칼슘 설포알루미네이트 (Calcium sulfoaluminate) 수화물을 생성시켜 수시간 내에 높은 강도를 발현하게 된다 ${ }^{9}$ 초속경 벽돌은 XRD 20값 15.75 와 25.52에서 포 틀랜드 시멘트로 만들어진 벽돌과 다른 Peak가 스펙 트럼에서 관찰되며 이러한 Peak들은 Calcium Iron
Oxide $\left(\mathrm{Ca}_{4} \mathrm{Fe}_{9} \mathrm{O}_{17}\right)$, Ettringite $\left(\mathrm{Ca}_{6} \mathrm{Al}_{2}\left(\mathrm{SO}_{4}\right)_{3}(\mathrm{OH})_{12}\right.$. $\left.26 \cdot \mathrm{H}_{2} \mathrm{O}\right)$, Corundum $\left(\mathrm{Al}_{2} \mathrm{O}_{3}\right)$ 의 주 성분으로 해석되었 다(Fig. 6). 이와 같은 분석결과는 실제 초속경 시멘트 로 제조된 증거품 혹은 벽돌 분석에서 일반적인 포틀 랜드 시멘트로 만들어진 벽돌과 달리 특정 $2 \theta$ 값을 나타내므로 구별과 분석이 용이해진다.

동양과 한라의 시멘트로 제조된 벽돌의 XRD 비교 분석 또한 건조 방법과 상관없이 Peak Intensity의 강 도에 차이가 있을 뿐 동일한 스펙트럼 패턴을 보였으 며 쌍용의 포틀랜드 벽돌 스펙트럼과 동일하였다. 그 러므로 XRD로 분석한 총 14 종류 벽돌의 원료 성분 유형은 시멘트 원료의 분류 유형(Type A와 Type B) 과 동일하게 분류된다. XRF을 이용하여 분석한 벽돌 의 화학 구성성분에서 $\mathrm{CaO}$ 의 함량에 비해 $\mathrm{SiO}_{2}$ 의 함 량 증가하였는데 이는 벽돌 제조 시 혼합하는 모래의 주성분인 $\mathrm{SiO}_{2}$ 의 증가에 기인된 것으로 보인다. $\mathrm{Al}_{2} \mathrm{O}_{3}, \mathrm{Fe}_{2} \mathrm{O}_{3}, \mathrm{Na}_{2} \mathrm{O}, \mathrm{MgO}, \mathrm{SO}_{3}$ 는 벽돌 제조전과 제조 


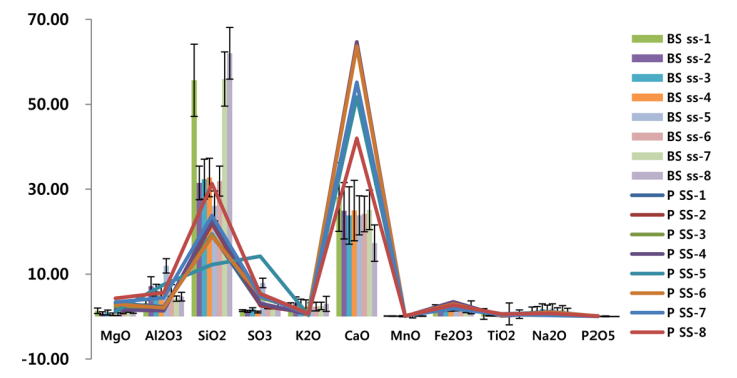

Fig. 7. Comparison of chemical properties of cement powder and Brick stones. The pellets of Brick stone (BS) and Cements Powder $(\mathrm{P})$ were measured by XRF. The increase of $\mathrm{SiO}_{2}$ for bricks shows the brick are contained in sand.

후에도 함량에 변화가 관찰되지 않고 동양과 한라 제 조사의 시멘트와 벽돌에서도 동일한 결과가 관찰된다 (Fig. 7). XRF를 이용한 벽돌의 구성 원소에 대한 분 석만으로는 벽돌 종류의 구별이 용이하지 않으므로 성분 함량에 따라 분류된 여러 벽돌 데이터 변수들 중에서 서로 연관성이 있는 변수들끼리 선형 결합 형 태로 묶어 분류하고자 하였다. PCA 통계학 분석을 수 행하여 시멘트의 조성 성분에 따른 벽돌의 종류를 구 분 할 수 있는데 시멘트 원료에 대하여 PCA 결과와 동일한 조건에서 벽돌의 $\mathrm{PCA}$ 수행 결과는 크게 두 가지 종류로 분류 할 수 있었다(Fig. 8(a)). 또한 PLS$\mathrm{DA}$ 의 통계 기법을 이용하면 저발열 시멘트와 고로슬 래그 시멘트로 제조된 벽돌과 쌍용의 $2,3,4,6$ 종의 시멘트로 만들어진 벽돌, 초속경 벽돌들의 세분화 분 류가 가능하다. 그러나 시멘트 원료성분 분석을 통한 주성분 통계학적 분류와 벽돌의 분류는 동일한 결과
값을 가지지만 벽돌의 경우에는 시멘트 원료에 비해 화학 조성 별 경계기준에 의한 분류가 명확히 되지 않았다(Fig. 8(b)). 따라서 벽돌의 XRF를 이용한 성분 분석과 함께 $\mathrm{XRD}$ 를 이용한 구조분석 결과를 병행함 으로써 분명한 분류의 결과를 기대할 수 있다.

\section{3. 제조사별 시멘트와 벽돌의 비교 및 분석}

본 실험에서 $\mathrm{XRD}$ 와 $\mathrm{XRF}$ 를 이용하여 종합 분석 한 결과로부터 벽돌은 크게 두 가지 타입(Type 1과 Type 2)으로 나누어지므로 두 가지 타입의 벽돌과 이것의 각 시멘트 원료와의 스펙트럼 비교 분석이 가능하였다. 쌍용 벽돌(SS-1)과 포틀랜드 시멘트 원 료 (SSANGYOUNG-1)와 나머지 다른 타입의 초속 경 벽돌 (SS-5)과 이것의 초속경 원료 시멘트 (SSANGYOUNG-5)의 XRD 분석을 시도했다. 포틀랜드 시멘트 와 이 원료로 제조된 벽돌의 스펙트럼 비교 분석 결과 는 다음과 같다. SS-1 벽돌의 주성분은 높은 강도의 Peak를 갖는 Quartz 모래 $\left(\mathrm{SiO}_{2}\right)$ 이고 (빨간 라인) 포틀 랜드 성분은 포틀랜드 시멘트 원료 (SSANGYOUNG11) 스펙트럼에 비해 낮은 Intensity 세기를 보였다 (파란 하향 화살표)(Fig. 9(a)). 또한 벽돌 스펙트럼은 포틀랜 드 시멘트 원료 스펙트럼과 3개 영역에서 다른 29값 이 관찰되고(분홍색 원형) 18.03 (Calcium Aluminum Oxide, $\mathrm{Ca}_{12} \mathrm{Al}_{14} \mathrm{O}_{32}$ ), 27.49 (Zinc Germanium Seleride), 36.43 (Gallium Oxide, $\mathrm{Ga}_{2} \mathrm{O}_{3}$ ) 주성분 Peak로 나타난 다. 초속경 벽돌 SS- 5 를 제외한 그 밖의 쌍용 시멘트 로 제조한 각각의 벽돌 스펙트럼과 원료 스펙트럼의 비교는 Fig. 9(a)의 스펙트럼과 동일하였다. 단, 동양과 한라에서는 쌍용의 포틀랜드 시멘트(SSANGYOUNG-

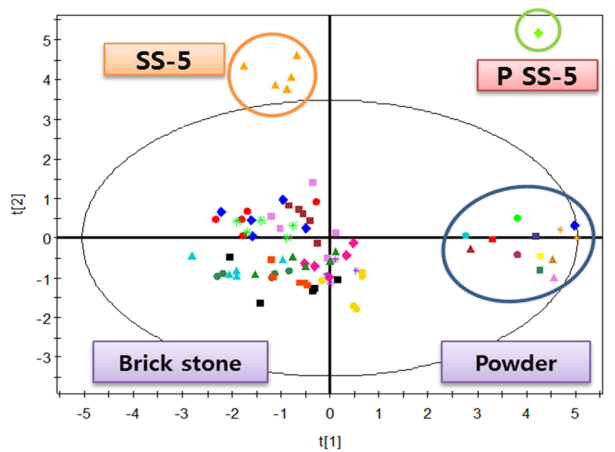

(a)

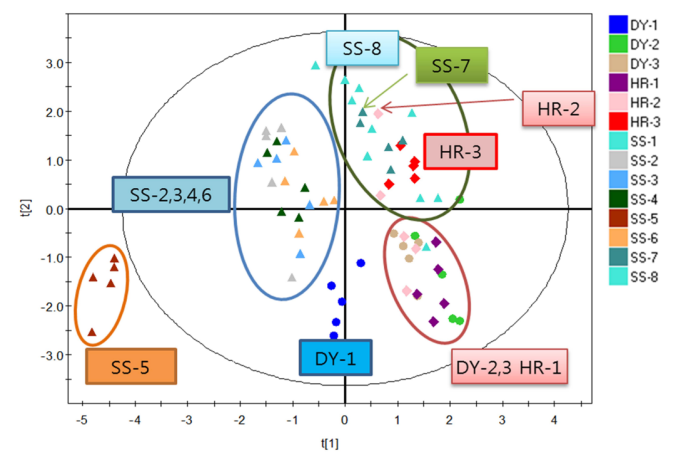

(b)

Fig. 8. (a) and (b). The PCA-X score plot of overview model of Brick pellets data set measured by XRF analysis. (a) There are two groups divided in SS-5 cement and the others according to statistical data from properties of chemical component. These group were computed, giving the performance indicators $\mathrm{R}^{2} \mathrm{X}[1]=0.369 \mathrm{R}^{2} \mathrm{X}[2]=0.174$, (b) The PLS-DA modeling divided 5 types of group for Brick pellets in details (Portland blast-furnace slag, Low heat hydration blended, SS2, 3, 4, 6, DY-1 and Ultra super early strength brick (SS-5)). 


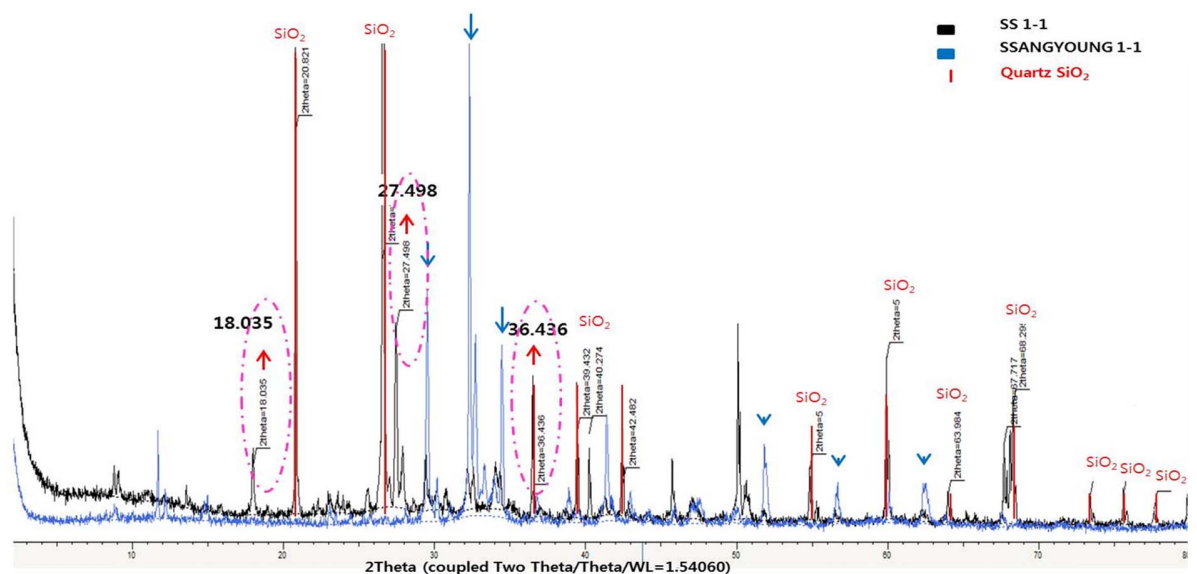

(a)

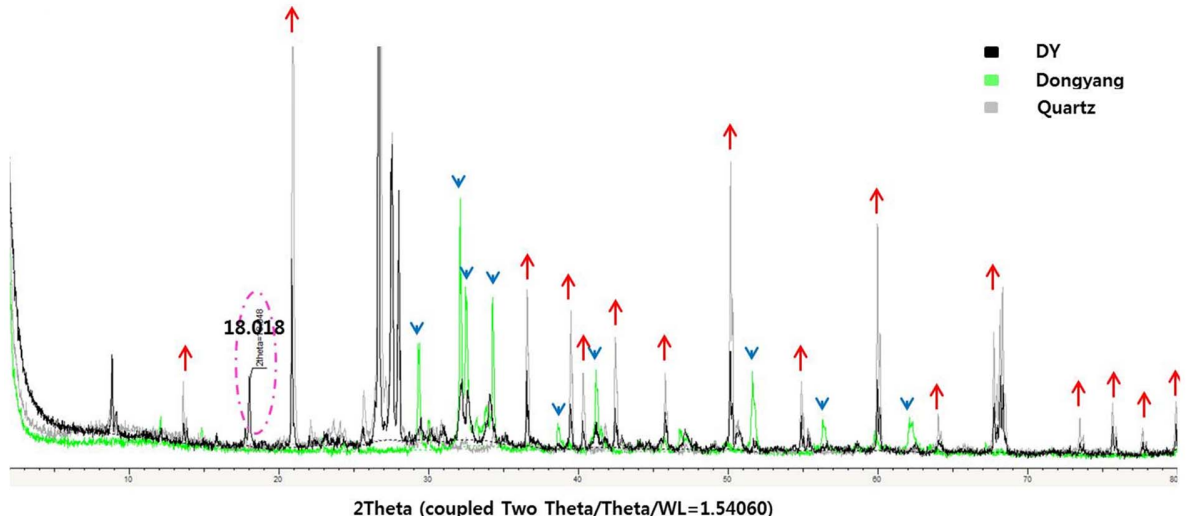

(b)

Fig. 9 (a) and (b) Comparison of Cements and bricks by overlapping spectra by XRD analysis. The different peaks were observed after overlapping spectra of cements and bricks.

1)가 아닌 각각의 제조사 시멘트와 비교 분석 할 경우 원료의 성분과 다른 1 개의 18.05 의 20 값이 관찰되었고 Calcium Hydroxide $\left(\mathrm{Ca}(\mathrm{OH})_{2}\right)$ 로 확인되었다(Fig. 9(b)).

초속경 시멘트(SSANGYOUNG-5)와 이것으로 제조 된 벽돌(SS-5)의 XRD 비교 분석 결과는 다음과 같다 (Fig. 10). 벽돌 제조 후 초속경 시멘트 원료에 비해 Peak의 세기가 작아지나 20값 20과 50사이 영역에서 Calcium Aluminium Oxide Silicate와 Calcium Silicate 잔류량이 여전히 남아 있었으며 주성분인 모래와 초 속경 시멘트 원료와 비교 분석하면 시멘트 원료 스펙 트럼과 다른 $2 \theta$ 값 $9.06,13.64,18.94,27.95$ 는 각각 주성분으로 Ettringite, Aluminum Manganese Silicon, Calcium hydroxide로 확인되었다. 특히 $2 \theta$ 값 9.06은 Ettringite $\left(\mathrm{Ca}_{3} \mathrm{Al}_{2} \mathrm{O}_{6} \cdot 3 \mathrm{CaSO}_{4} \cdot 32 \mathrm{H}_{2} \mathrm{O} ; \mathrm{C} 3 \mathrm{~A} \cdot 3 \mathrm{CS} \cdot 32 \mathrm{H}\right)$ 로 분석되고 이는 초속경 시멘트에 물이 가해지면
$\mathrm{Ca}(\mathrm{OH})_{2}$ 와 무수석고 등과 반응하여 $\mathrm{Al}(\mathrm{OH})_{3}, \mathrm{CaO}$ $\mathrm{Al}_{2} \mathrm{O}_{3} \cdot \mathrm{H}_{2} \mathrm{O}, 3 \mathrm{CaO} \cdot \mathrm{Al}_{2} \mathrm{O}_{3}, \mathrm{CaO} \cdot \mathrm{SiO}_{2} \cdot 12 \mathrm{H}_{2} \mathrm{O}$, 등의 수화물을 생성하기 시작하여 이 수화물은 $\mathrm{CaSO}_{4}$ 의 용해분과 연속적으로 반응하여 Calcium Aluminium Monosulfate 또는 Ettringite를 생성하여 우수한 초기강 도를 발현하게 된다. ${ }^{10}$ 다른 비교 분석법으로는 초속 경 시멘트 원료에는 강화제 성분이 포함되어 있는 경 우가 많으므로 초속경 시멘트로 제조된 벽돌은 특징 적 강화제 성분인 수화물 성분의 비교 분석을 위해 원료 시멘트가 아닌 포틀랜드 시멘트 원료와 비교함 으로써 그 특징을 더욱 쉽게 구분 할 수 있었다. 포틀 랜드 스펙트럼과 다른 $2 \theta$ 값이 $9.05,15.71,18.88$, 22.87, 35.04이며 모두 Calcium sulfoaluminate 수화물 Ettringite의 스펙트럼과 일치한다(Fig. 11). 따라서 초 속경 시멘트로 제조된 벽돌의 경우 일반적인 포틀랜 


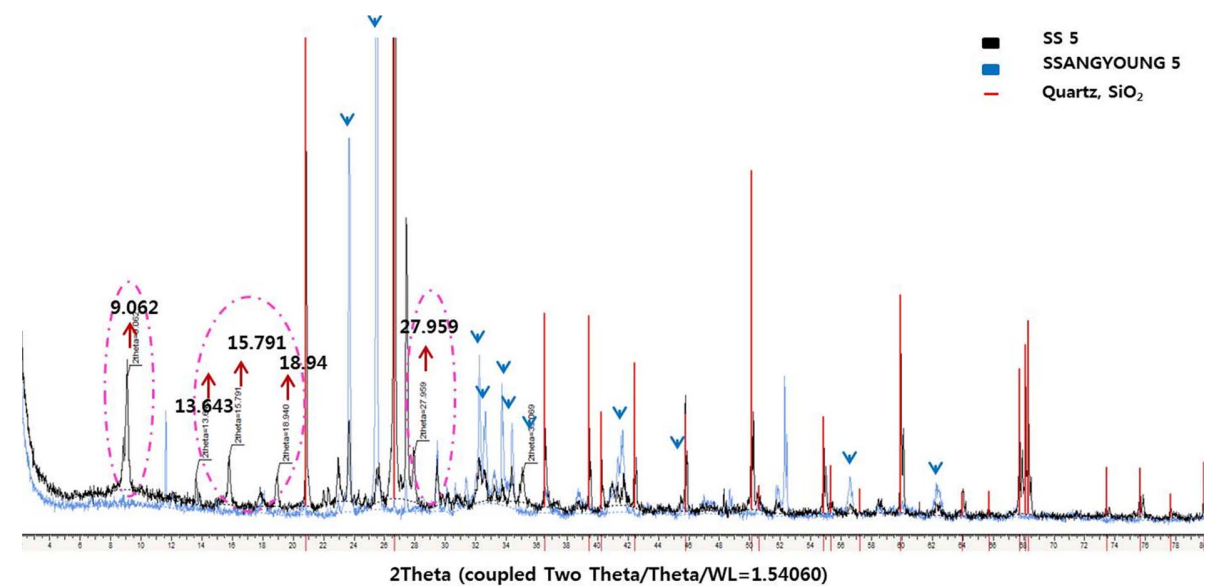

Fig. 10. Comparison of Cement (SSANGYOUNG-5) and Brick stone (SS-5) by XRD analysis.

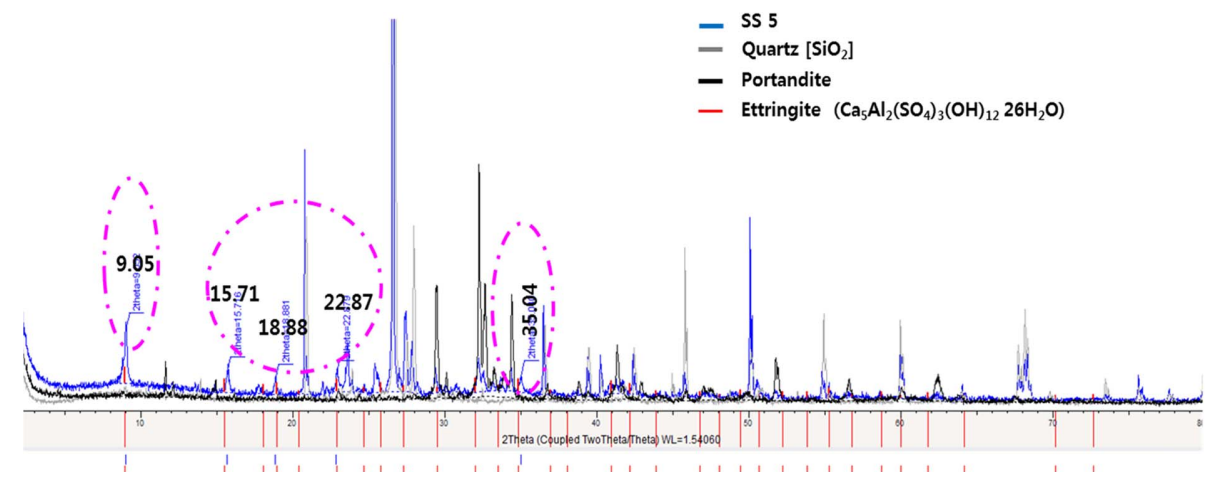

Fig. 11. A XRD spectra of Ultra super early strength brick is compared with overlapping spectra of portland cement clinker and Ettringite.

드 시멘트 원료와 비교하거나 강화제 수화물의 성분 분석으로 식별이 가능하였다.

\section{4. 결 론}

시멘트에 대한 화학적 정보와 제조사 및 종류의 분 류를 위한 변별력 검토를 얻기 위하여 XRD와 XRF의 종합 분석을 실시하였다. 제조사별 14 종류의 시멘트 에 대한 다음과 같은 결과를 얻었다. XRD 데이터를 통한 시멘트의 분류는 초속경 시멘트를 제외한 나머 지 시멘트 두 분류로 나누어지며 XRF 데이터를 근간 으로 한 통계학적 PCA방법을 수행하면 초속경 시멘 트뿐만 아니라 초조강 및 고로슬래그 시멘트의 세부 분류가 가능해진다. 14 종류의 시멘트 원료로 제작된 벽돌 또한 $\mathrm{XRD}$ 와 $\mathrm{XRF}$ 의 데이터의 $\mathrm{PCA}$ 를 수행하여 종합 분석결과 벽돌의 종류가 좀 더 세분화되어 분류
됨이 확인되었다. 본 실험을 통하여 제조사 및 종류를 알 수 없는 벽돌의 감정 및 분석방법으로 i), 시멘트에 대한 정보가 없는 경우, 일반적인 포틀랜드 시멘트와 벽돌의 스펙트럼을 비교하여 겹치지 않는 피크의 패 턴으로 벽돌의 종류를 분석하는 것이 가능하며 ii), 원 료 시멘트에 대한 정보를 아는 경우, 벽돌과 시멘트를 비교하여 벽돌의 종류 및 성분에 대한 분석을 할 수 있었으며 제조사에 대한 정보 및 시멘트 원료와 벽돌 성분 이외의 특정 미량 성분을 분석해 낼 수 있었다. 이렇게 분석된 시멘트 데이터들은 표준 시료로 응용 되고 다양한 시멘트 페이스트 증거물들과 비교 자료 로 활용되어 수사의 정보 활용에 이용 될 수 있다. 보 다 다양한 시멘트와 벽돌에 대한 정보를 얻기 위하여 다른 타 제조사의 시멘트 및 벽돌 증거물에 관한 구 성원소 및 특정 원소에 관한 성분 분석이 이루어야 할 것이다. 또한 벽돌 제조시 첨가되거나 변성된 성분 
에 대한 정보와 특정 구성 성분은 법과학적 분석 측 면에서 중요한 추적자료가 될 수 있다. 객관적인 결과 를 얻기 위하여 본 실험 결과와 제조사별 실험 분석 결과와 비교 검토할 필요가 있으며 이렇게 얻어진 정 보 데이터(Cement data library)를 구축하여 미지의 시 멘트 또는 벽돌 증거물에 대한 분석에 대한 분별력과 정확성을 기대할 수 있다.

\section{감사의 글}

본 연구는 한국연구재단의 지원을 통해 수행하였기 에 감사의 말씀을 전합니다(NRF-2012-0009832).

\section{참고문헌}

1. 안주옥, 서영갑, '근 콘크리트 공학 제 1장 철근콘크 리트공학 개론, 사이텍 미디어, 2008.

2. H. F. W. Taylor, 'Cement Chemistry', 2nd Ed., Academic Press, 1997.
3. P. Stutzman, Natl. Inst. Stand. Technol. Tech. Note 1441 (2002).

4. A. A. Tabikh and R. J. Weht, Cement and Concrete Research, 1, 317-328 (1971).

5. K.-K. Choi, Lik Lam and Shiu-fai Luk, Talanta, 41, 18 (1994).

6. D. Bonvin and R Yellepeddi, Advances in X-ray Analysis, 42, 126-136 (1992).

7. Richard A. Johnson and Dean W. Wichern 'Applied Multivariate Statistical Analysis' 6th Ed., Prentice Hall Press, 2002.

8. L. Eriksson, E. Johansson, N. Kettaneh-Wold, J. Trygg, C. Wikstrm, and S. Wold, 'Multi- and Megavariate Data Analysis Part I. Basic Principles and Applications', Umetrics Academy Press, 2006.

9. 김병기, 김준영, 문지환, 이상수, 송하영, 대한건축학 회지회연합회 학술발표대회논문집, 533-538 (2011)

10. T. D. Dyer, J. E. Halliday and R. K. Dhir, J. Mater. Sci., 34, 4975-4983 (1999). 